\title{
FROM SEXUAL COMMUNITY TO EXCLUSIVE SEX: SEMIOTIC TRANSLATION ON GAY CHAT AND DATING APPLICATIONS
}

\author{
Francesco Piluso \\ Alma Mater Studiorum - University of Bologna, Italy \\ CRAAAZì - Centro di Ricerca Archivio Autonomo Alessandro Zijno \\ francesco.piluso2@unibo.it
}

\begin{abstract}
"Gay, bi, trans, and queer" chat and dating apps, since explicitly addressed to sexual categories, are inevitably permeated by "sex", even though this word rarely appears in the presentations of these applications. This omission is quite significant, since it establishes a strict code of interpretation and use for many of these apps, which usually promote a one-to-one heteronormative mode of interaction, in which sexuality, rather than a social bond, is intensively privatized and exclusive.

The architecture of these apps deceptively seems to promote both the identity of the single user and the formation of communities through the possibility (and the necessity) of filling a series of categories. Actually, these categories and provided data, related to a mechanism of filters, combine to orient and standardize users' choices and, consequently, the sexual and social value of the users themselves.
\end{abstract}


These apps, through the (self)exploitation of their users, establish a gentrification process of their virtual spaces to increase their rental value as platforms. In this circular mechanism, a recursive hierarchy between a platform and its users is traceable, as well as amongst the users themselves.: racist, anti-feminine, transphobic and sierophobic behaviors are dissimulated and legitimated as mere personal tastes. Therefore, while performances of white masculinity are awarded at the prize of frustrating normalization, "trans" and broadly "queer" subjectivities, widely sponsored by the queerwashed pages of these apps, are in fact excluded.

Through a semiotic analysis of Grindr and PlanetRomeo, two of the bigger gay apps, the aim of this work is to highlight the semiotic processes of translation of sexual minorities' collective instances into commodified profiles. A mechanism that reflects a broader heteronormative and neoliberal process of re-appropriation and assimilation of the difference.

Keywords: gay apps, queer community, privatization, self-exploitation, model user

\section{Introduction}

Applications for "gay, bi, trans, and queer people" - this is the headline of Grindr, one of the most important gay chat and dating apps - apparently offer an open and safe space to share and perform his/her own gender and sexuality, to meet other $G B T Q$ people, and to express the sexual bond which defines this social target. Nevertheless, the explicit reference to sexual minorities does not match an explicit reference to sex. This omission is significant since it empties the sexual community of its social bond related to sex, but, at the same time, it exploits sex and sexuality in terms of transgressive sexual appeal to attract users. In other words, the richness of LGBTQ sexual communities is reduced to a market field of attraction for masculine profiles, in which sex and sexuality become highly privatized and exclusive.

A semiotic perspective is helpful in comprehending this process. I will use tools of structuralist semiotics in order to analyse the intersection of text and images - a relationship that expresses the broader mechanism of translation (and assimilation) of queer contents within the platform structures and neoliberal forms of commodification. Secondly, through an interpretative and pragmatic semiotic perspective, I will analyse the intrinsic strategies of interpretation within the structure of apps and adopted by users to reproduce the mechanism of translation. Therefore, translation (Lot- 
man [1985] 2005) and interpretation (Eco 1979b) are two sides of the same coin in which the two semiotic perspectives can work together.

The main category upon which this work is based is sexual community vs. privatized sex. The two terms of this category do not have a relation of reciprocal exclusion, but they share some semantic features in "participatory opposition" (Hjelmslev 1985; Paolucci 2010). Indeed, the reference to a glossy (market-fit) idea of sexual community, abstracted from its sex content, is necessary to implicitly promote the privatization of sex itself. In other words, the promotion of exclusive sex is a parasite of the purified "myth" of sexual community (Barthes [1957] 1972).

The social meaning, the sense of this dynamic, is lent by the syntactic operations applied to the main category (Greimas [1970] 1987). Therefore, the aim of this work is to analyse the passage (and its implications) from sexuality as social bond to sex as privatized interaction. This process is not conducted as a mere abstract operation; users are in charge of reproducing the mechanism of translation through their work, within the neoliberal ideology of exploiting differential individualities. Nevertheless, their individual agency is a simulation: the same strategy of interpretation and use is built by apps' architecture itself.

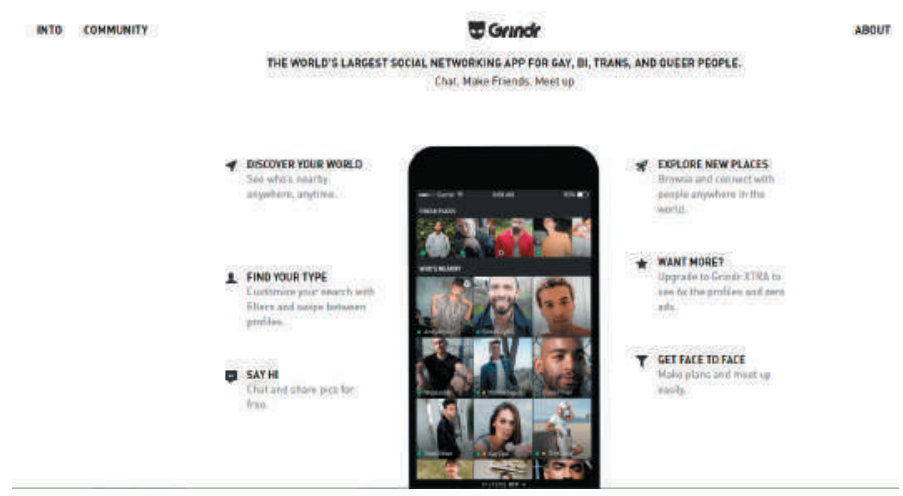

Fig. 1: Grindr website homepage

\section{Sexy fake ambiguity}

In its website homepage (Fig. 1), Grindr promotes itself as a virtual space for GBTQ people to "chat, make friends, meet up". The GBTQ community is recognized as a target for social activities. Seemingly, throughthough an obvious commodification of the service provided by the app, there is an acknowledgement of sexual minorities' issuesissue as a social, somehow public, field. Nevertheless, the word sex does not appear publically. There is still another ambiguity - if sex is never explicitly quoted, it is, at the same time, implicitly and overtly conveyed by the image(s) of Grindr. 
Plenty of symbols and icons with a sexual allusion populate the scenery of Grindr. These signs are used to soften the reference to sex, obfuscating this interpretative connection. Actually, they operate as a re-contextualization of the content /sex/ in order to exploit it. For example, the image of the yellow mask (Fig. 2) is the actual logo of Grindr. It is an allusion to sex as something transgressive, that has to be masked, thus becoming even more transgressive (a personal supposition legitimated by the cultural meaning of the mask as a symbol for sex).. Such a symbol activates and exacerbates a really traditional, heteronormative semantic spectrum of the sign /sex/, focused on the value of "privacy". Therefore, the issue of sex is not eliminated, but re-contextualized from a public/social sphere to a private one.

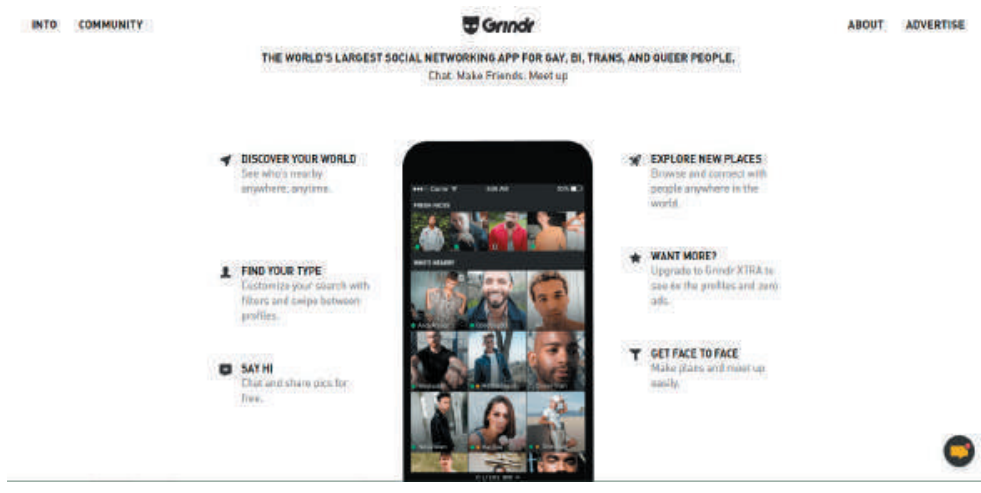

Fig. 2: Grindr website homepage

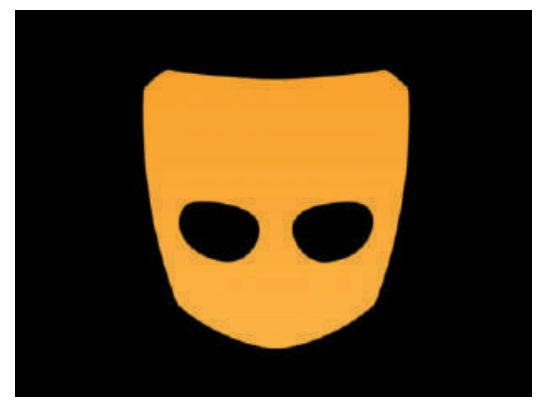

Fig. 3: The logo of Grindr 
This pattern becomes even clearer looking at the Italian homepage of PlanetRomeo, another very popular gay application (Fig. 3). "Dates, friends, love", as in the previous example, are semantic isotopies belonging to the same semantic field (Greimas 1984): they are personal activities with a social/public connotation, explicitly quoted in the website homepage. Yet, "sex" does not appear, but its content and value is conveyed by the website's imagery.

A sexy naked guy looks at us, with a complicit gaze, malicious in his apparent innocence. Behind him, the blurred image of another man shows their sexual intimacy. The same dynamic is reproduced: a softened intimate sexual image reinforces and makes explicit the game of malice and transgression. Sex is publically showed and clearly displayed through a blurred, private image, in a paradoxical game of fake ambiguity.

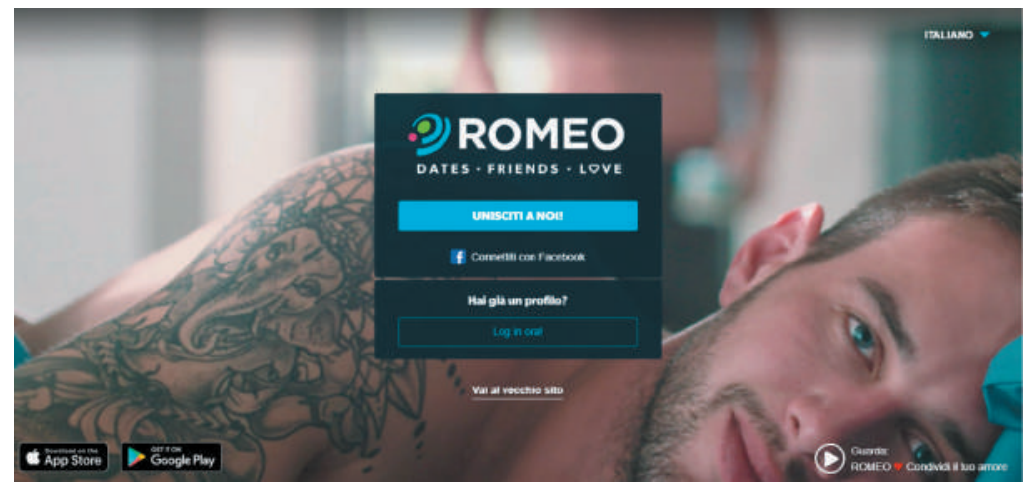

Fig. 4: PlanetRomeo website homepage

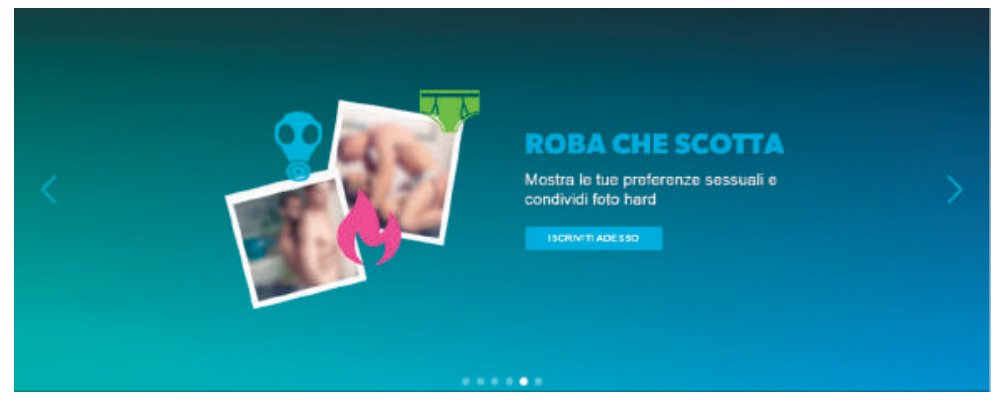

Fig. 5: 'Roba che scotta' window

Browsing downwards, on the same webpage, there is a catalogue of windows that show and promote some of the app's functions. The first window says "roba che scotta", literally 'hot stuff', and explains how the user can share his own sexual tastes and "hard" pictures. Even though the content of this function is clearly sexually-oriented, once again, the imagery of sex is 
built implicitly through the use of metaphor "hot stuff" itself, and through two blurred pictures of men having sex. The second emblematic windows, "va a caccia", literally 'go hunting, metaphorically 'find people to have sex with', demonstrate how to use the footprints instrument, confirming the animal metaphor to activate and reinforce the "wild" and "savage" side of sex, without naming it explicitly.

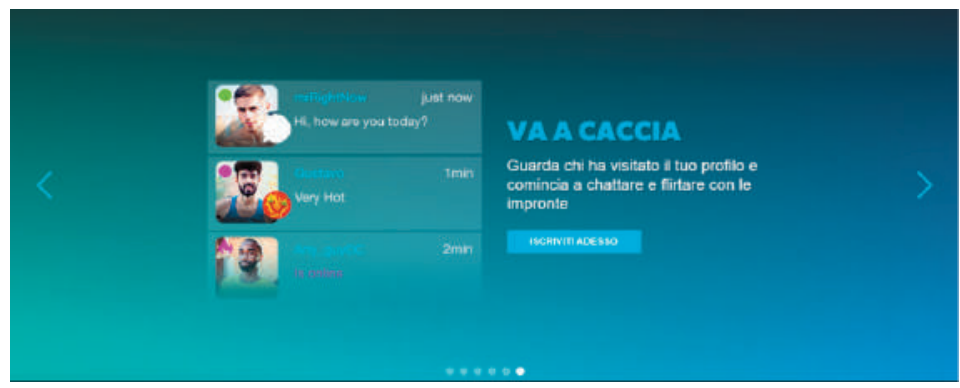

Fig. 6: 'Va a caccia’ window

\section{Sexual exchange value of differential identities}

To this purpose, "footprints" are very meaningful devices. They are iconic and symbolic pills of sexual messages, used to flirt and usually to start a private one-to-one interaction. Footprint are winks; they privately convey complicity, which is sexy. Therefore, the imagery of sex is apparently softened and made funny by the term "footprints", but not mystified.

The use of footprints, beyond the issue of imagery, is a key factor in the process of privatizing sex. As previously stated, footprints are used by one user to contact another. Actually, this private one-to-one interaction between two users through footprints is at the base of a social network amongst the entire community of users. Indeed, PlanetRomeo draws up and constantly updates its "top footprints" rankings. Each chart, related to a single footprint, establishes a user's rank according to the number of footprints they received. This mechanism favors the targetization of the users, and the standardization of their tastes in terms of quantitative values. The sexual exchange value of each profile is extablished in relation to the value of the other users, as in a system of commodities. In this regard, it is peculiar and noteworthy that the only way for public socialization, beyond private one-to-one interaction, is commodification - that is, another form of privatization. Indeed, this social/public structure is useful for orienting the user's private choice in terms of consumption-sending further footprints and establishing new private interactions-thus reinforcing the entirecircular mechanism. 


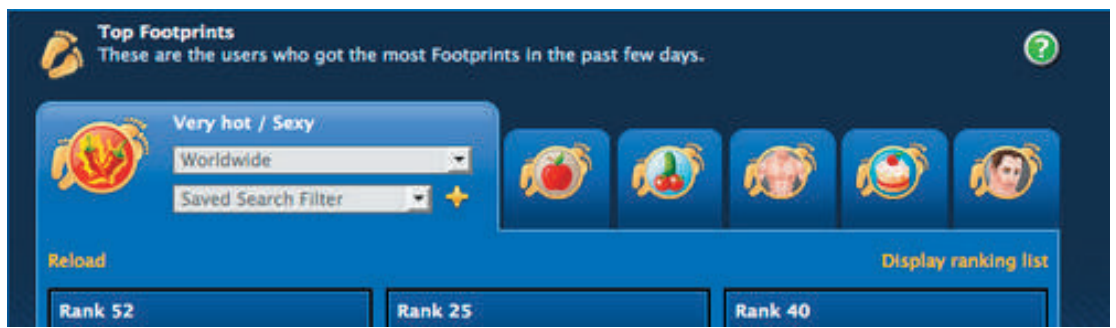

Fig. 7: footprints

The production of user value starts with the construction of a personalized profile. As in many other social networks, the first step in entering the community of users is to fill a series of categories related to personal qualities. In the case of these two applications, the list of categories is very rich and detailed. Main categories are related to general physical features, such as weight, height, colour of skin, eyes, hair, and more specific ones, as the size of your genitals - still not nominated. Then there is age, which usually appears on the main page of the profile, being one of the principal parameters of identification and selection. Much attention is given to the sexual aspect through categories such as sexual orientation, preferred sexual positions or role, and fetishes. Personal tastes and attitudes occupy the bottom part of the profile, often replaced by a blank space in which the user can provide a brief description of himself, though often used to convey further explicitly sexual information.

Nevertheless, the possibility of constructing a very detailed profile that could reflect the personal identity of the user is just an instrumental alibi. Indeed, the profile is the first window through which is necessary to promote one's own user-value. These mechanisms of commodification lead users to adapt their own profiles to the market standards fostered by these platforms. In other words, every user has to fit the catalogue of the high-value profiles/ products to effectively join the app's community. As in the case of commercial communication, the profile has to briefly display its own value, mainly in terms of sex appeal. Users are aware that they are selected by other users exclusively according to the pictures they provide, in most cases.

The social value of LGBTQ people lies in their difference, and in the necessity and right to find a social space to freely express such a difference. These applications privatize this space of agency by replacing the idea of a queer social community with an individualized "simulacrum" (Baudrillard [1981]1994): a customizable profile, continuously subjected to mechanisms of standardization and commodification. It is not a coincidence that the rich list of categories is tied to a system of filters. Users are selected in relation to the data they provide, according to the personal tastes of other users. Never- 
theless, tastes, rather than an issue of personal preferences, are structurally determined by the architecture and the imagery provided by these platforms.

Another key function of these categories is the creation of what are usually defined as "communities". Rather than reflecting the variety and the queerness of the GBTQ community, platform communities are groups of homogenous profiles generated according to the data requested. This mechanism leads to further standardization and division, with the creation of exclusive groups and consequently of excluded profiles. It is peculiar that in Grindr, these groups are called "tribes", and the names of many of these tribes, such as "bear" and "otter", reflect this racialized, almost animal, imagery. As already stated, this metaphorical exotificationexotization is aimed at sexualizing the user. After all, communities and tribes are merely translated into a further specific category - as any other category, this is exclusively aimed at increasing the profile's sexual value. There is no actual creation of communities, only the implementation of another index to foster the one-to-one sexual interaction. In the specific case of the "tribe" category, it is the private interaction between alike profiles that exemplifies this pattern of exploiting the concept of community to reproduce the one-to-one relationship mode.

\section{Hetero/homonormativity and queerwashing}

The privatization of the social bonds related to sex and sexuality in these various forms, and through these mechanisms, weakens the possibility of a non-conformist mode of social and sexual interaction, damaging the value of queer subjectivities and community. This dynamic fosters heteronormative relationship patterns and standardization of sexual tastes. If it is still possible to be gay in a gay chat and meeting app, the user has to be/act as a "real man" who likes other "real men". This is the way in which heteronormativity (as regards the normativity of gender roles and sexual behaviors) meets and fosters homonormativity (in terms of the standardization and homogenization between male partners) in another participatory category.
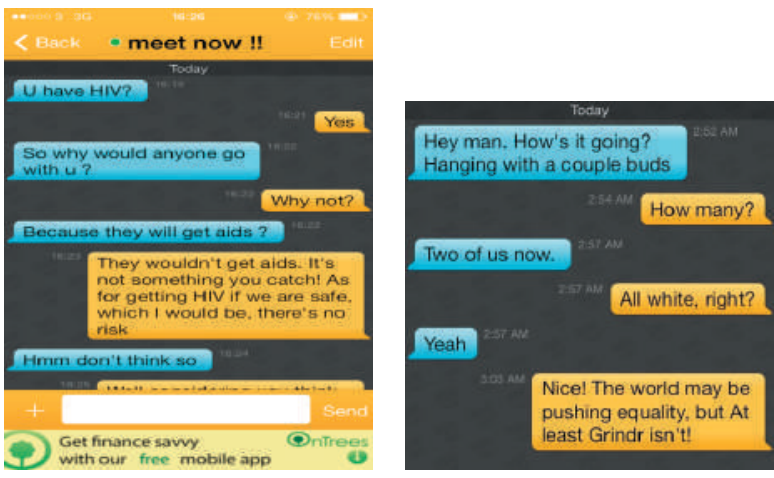

Fig. 8: discriminatory conversation 
Such a participatory opposition leads to the "MxM", or "M4M" - masculine for masculine - phenomenon. This is a widespread and explicit attitude of gay users who perform a hard kind of masculinity and look for the same. This phenomenon is both cause and consequence of two interrelated dynamics: frustration over achieving this key standard of social acceptability and sexual value; and discrimination of non-conforming profiles, such as queer, trans ${ }^{\star}$, feminine, old, fat, HIV-positive, and racialized users. To soften this widespread and manifest discrimination, users often resort to stereotypes - "no daddy" (to indicate old people), "no chocolate", "no rice", "no spice" (referring to specific racialized groups), etc. As in the case of sex, the use of these metaphors reinforces and privatizes the discriminating act. Indeed, discrimination is often justified in terms of "personal taste", which obfuscates the social and structural nature of this attitude.

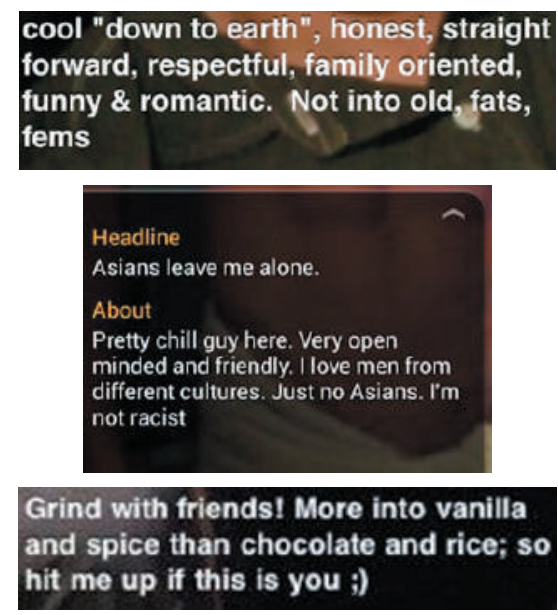

Fig. 8: discriminatory profiles

Both Grindr and PlanetRomeo have recently tried to overcome this problem of discrimination and racism amongst users in their platforms by fostering the myth of the queer community. In particular, Grindr has changed its main demo picture: from a catalogue of very masculine, muscular, young and mostly white profile (Fig. 9) to a more varying group of broadly GBTQ profiles (Fig. 10). 


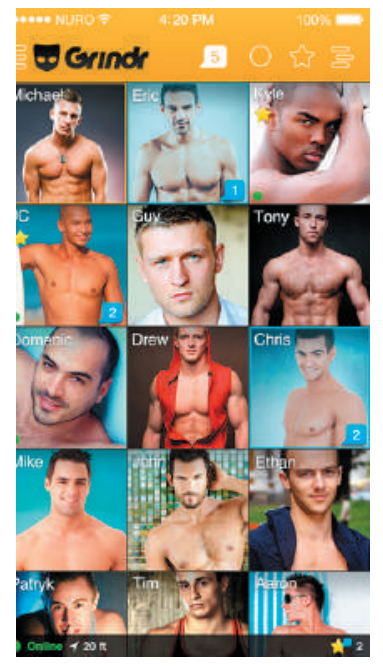

Fig. 9: Grindr previous demo picture

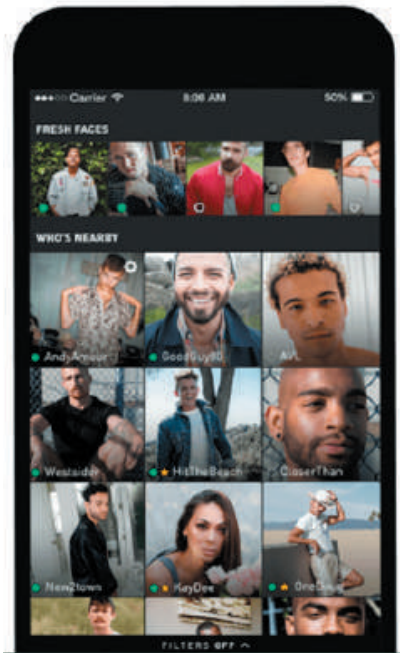

Fig. 10: Grindr new demo picture

A twink boy, two black guys ${ }^{1}$ and a trans woman are isolated examples of the variety and heterogeneity of the community that this application wants to promote. Nevertheless, the problem with this operation is not in the content being represented, but in its formal structure. Indeed, the idea of queer community, characterized by an intersectional perspective, is translated in a grid of tokens that cannot reproduce its across-the-board specificity. Broadly queer subjectivities (racialized people included) do not represent a minority share within the group; queerness is not an issue of single identities but an attitude that characterizes the community as a whole.

Once again, through the architecture and the imagery provided by these applications, the contents of queerness are translated and recontextualized in new forms - robbed of their specific meanings and values, these contents are not destroyed, but used as alibi, as legitimation for the ideological operation that privatizes queerness itself. These queer token-users, within the rigid structure of commodities, have the function to "inoculate" (Barthes 1972: 150) a little dose of queerness to make the platform community immune to queerness as a whole. This way, platforms and their gay users can deceptively embrace queerness. Stripped of its own specific form and values, queer community becomes an ideological myth (Barthes 1972).

\footnotetext{
${ }^{1}$ Two black guys were already present in the previous demo picture of Grindr. Nevertheless, in this new demo, the black profile is no longer highly sexualized.
} 


\section{Gentrification of virtual space}

The operation of queerwashing remains a superficial glamour spot for these applications, without challenging their structural and ideological pillars. Paradoxically, constructing a myth of queer community is compatible with both heteronormative and private structures, and both work to increase the applications' (economic) value. The phenomenon that combines both these elements is the gentrification ${ }^{2}$ of the virtual space. When gentrified, the underground, peripheral and non-conforming aspects of virtual space, related to their queerness, are purified and made mere window to both cover and exalt the structure's neoliberal core. While the applications work to present themselves as queer, at least superficially, users are induced to maintain the virtual space clean from all eccentricity and excess. As already stated, users are pressed to a constant task of self-valorization and evaluation of the other profiles: this mechanism results in the performance of hard masculinity and the exclusion of eccentric subjectivities. The ideological value of decency induced by these platforms and performed through the work of their users is at the base of the gentrification and the valorization of the platform itself.

What users can see through the application is a new map of the geographical area, which establishes the gay value of the place itself. Nevertheless, this index does not describe the actual composition and distribution of the GBTQ community around the city, but instead reflects the access and the visibility of GBTQ people in social space through structural mechanisms like filters, and ideological discourses of decency (and practices these induce). In other words, the map delivered by the application precedes the territory, establishing a new mode of pragmatic interpretations of gay life in a specific territory.

Abstraction today is no longer that of the map, the double, the mirror or the concept. Simulation is no longer that of a territory, a referential being or a substance. It is the generation by models of a real without origin or reality: a hyperreal. The territory no longer precedes the map, nor survives it. Henceforth, it is the map that precedes the territory - precession of simulacra - it is the map that engenders the territory and if we were to revive the fable today, it would be the territory whose shreds are slowly rotting across the map (Baudrillard 1994: 166).

Therefore, the gentrification of these virtual spaces reflects and reproduces the local processes of gentrification by public and private institutions concerning LGBTQ issues. Gay apps become a crucial dispositive for the production and naturalization of the policies of commercialization and normalization that gay spaces face - online and offline.

${ }^{2}$ For a deeper reflection on the widely debated issue of gentrification, Sharon Zukin (1987), David Harvey (2012) and Giovanni Semi (2015). 
To this effect, it is important to notice that sex work - already forbidden in much national legislation and relegated to a clandestine periphery - is highly stigmatized in gay virtual space. This ban exemplifies two interrelated mechanisms that characterize these online platforms. First of all, direct mentions of sex are not decent - sex has to be masked and covered: any explicit reference to sex as work would openly disclose the private aspect that sex acquires in these platforms behind and through the game of fake ambiguity. Secondly, personal profit for sexual activities is not allowed; the sexual work of the user is functional exclusively to the economic profits of the platform. This is a condition not only for strictly sex workers, but, more extensively, it concerns all the forms of sexual and gender work performed by the users. It is no coincidence that users themselves are the main agents in charge of banning and reporting sex worker profiles.

\section{Self-exploitation and valorization}

One of the wheels of this mechanism of users' (self)exploitation for economic profit off these applications has been recently unmasked in the media scenery. At the beginning of April, an inquiry by a Norwegian non-profit organization revealed that Grindr sells its users' private data to external companies. Even though Scott Chen, Grindr's chief technology officer, declared that sharing data has been an industrial practice to test and optimize Grindr software, and consequently to protect the privacy of the users, the purchase of data by Apptimize and Localytics suggests that the economic operation has been aimed to further market targeting of user profiles. The scandal has been mainly focused on the sale of data concerning users' HIV status. ${ }^{3}$ This aspect is peculiar since it demonstrates how even health becomes a commodity or standard to achieve through private consumption.

Even though this hypothesis of the data's sale for marketing purposes has not been proven, commodification and privatization of self-care is fostered by other structural and ideological dynamics. The hetero/homo-normalization of tastes and the relative standardization of their sexual and social value for users are a consistent push for users to work on their bodies. Users are influenced to shape their own bodies through the consumption of private goods and services. Self-care, and more widely social health, is

\footnotetext{
${ }^{3}$ Here are some references-links to the news:

https://www.independent.co.uk/life-style/gadgets-and-tech/grindr-hiv-status-usersthird-party-companies-stop-sharing-criticism-gay-dating-app-a8286366.html https://www.telegraph.co.uk/news/2018/04/03/gay-dating-app-grindr-scorched-handling-hiv-data/

https://www.bbc.com/news/technology-43624328
} 
thus subjected to privatization and becomes an issue of personal attitudes and lifestyle. In this regard, it is not a coincidence that today private gyms are one of the main social spaces for gay people. Furthermore, all this consumption of private services is spent to achieve and further increase the high physical standards of the applications: consumption thus becomes productive work for gay private companies.

The circuit of value of these platforms could work according to the scheme on Fig. 11:

The crucial issue around this circuit is that, even if users appear to have free agency, it is the architecture of the apps that foster and exploit users' practices. According to Umberto Eco's pragmatic semiotics, a text offers the reader paths of interpretation for itself: this strategy, which establishes a collaborative relation between the reader and text through the process of interpretation, is called "model reader" (Eco 1979b: 205; 1979a: 60). The model reader remains an abstract strategy, different from the concrete reader that stands outside the text. Nevertheless, a (virtual) space is a very peculiar semiotic text with a syncretic plane of expression, in which the model user ${ }^{4}$ doesdo not remain an abstract strategy shaped by the text's architecture, but directly singles outsingle the concrete user.

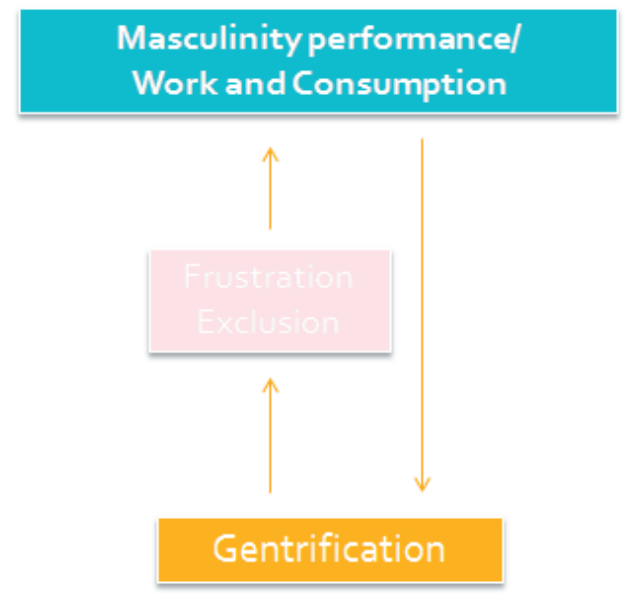

Fig. 11: circuit of exploitation and valorization

\footnotetext{
${ }^{4}$ Beyond the explicit reference to the concept of model reader by Eco (1979a), the notion of model user is borrowed from Violi's (2014) notion of model visitor.
} 
The real user is part of the plane of expression and a concrete agent for the creation of meanings and values within and for the platform ${ }^{5}$. This is the specific model of relation between gay apps and their users, but it can be potentially broadened to any other social network/applications. Moreover, the semiotic relationship of co-operation between the platform and user exemplifies the general strategy of the model user'

Ecco, ora si rompono gli indugi e questo lettore, sempre accanto, sempre addosso, sempre alle calcagna del testo, lo si colloca nel testo. Un modo di dargli credito ma, al tempo stesso, di limitarlo e di controllarlo.

(Hesitation is broken and this reader, always next to, hot on the heels of the text, is collocated within the text. A way to give him credits but, at the same time, to limit and control him).(Eco 1979b: 11)

The semiotic (and pragmatic) relationship between users and the platform produces a circuit of value in which specific hierarchical directions are traceable. The exploitation of users' work (and productive consumption) by the platform establishes the hegemony of the latter on the former. This asymmetry is reproduced, in a fractal recursivity ${ }^{7}$, within the of the users' community itself: white, fit, young and masculine profiles are selected for above non-conforming, queer and racialized subjectivities. These two relations of power are strictly interwoven, and mutually reproduced in a fractal and recursive circuit of exploitation and valorization.

\footnotetext{
${ }^{5}$ Make a comparison with the notion of "model visitor" (Violi 2014: 123).

${ }^{6}$ Indeed, this reflection is part of a wider debate around the role of users with(in) technological devices and structures. To this regard it is necessary refer to the semiotic studies around the notion of "interobjectivity" (Marrone 2002; Landowski 2002; Semprini 2002; Fontanille 2002; Ferraro 2002; Dusi, Marrone, and Montanari 2002; Latour 2002); to the academic and political controversy on subsumption of digital labour to capital (Berardi 2002, 2011; Fumagalli 2015; Griziotti 2016; Lazzarato 2014; Negri, Vercellone 2007; Pasquinelli 2009, 2009b; Raunig 2010; Vercellone 2006, 2007); and potentially to some theories and peculiar perspective on the dialectic between langue and parole (Barthes 1973 [1975]; Baudrillard 1972 [1981]; Eco 1979a, 1984).

${ }^{7}$ This expression and semiotic instrument of fractal recursivity is borrowed from the work of Irvine and Gal (2000) on linguistic ideologies. It indicates the projection of an opposition from one level to another, used to create an identity for a given group to further divide it (Irvin and Gal 2000: 38).
} 


\section{Conclusion}

Main gay chat and meeting apps, such as Grindr and Planet Romeo, reproduce a sophisticated and deceptive process of neoliberal privatization of GBTQ social space. The notion of sex, community, difference, queerness and identity are emptied of their nuclear values to be exploited by a mechanism of economic valorization in a private and commercial (semio)sphere.

The notions of participatory opposition, sexual and social exchange-value, inoculation and myth, queerwashing, tokenism vs. intersectionality, gentrification, simulacrum, and fractal recursivity are semiotic theoretical instruments useful for understanding the ideological operations and mechanisms through which these applications exploit the value of social difference and legitimate the privatization of sexual bonds: semiotic translation of the LGBTQ issue in differences within the neoliberal structure of (economic) valorization of difference itself (Baudrillard 1981).

The architecture of these platforms, in terms of one-to-one interaction, their filters and rating system, and their grid or catalogue of profiles, is strictly interwoven with the ideological imagery that these platforms promote: privatized and exclusive sex, hetero/homo normative models, and the tokenizing of queer identities and community. All these devices are implemented to exploit the work and the productive consumption of users within (and outside) these platforms.

Users themselves, and their self-exploitation, are the main mechanism behind the structural, ideological and economic reproduction and legitimation of these applications, as well as of the neoliberal context the platforms themselves reproduce.

\section{Acknowledgements}

Inspiration, suggestions and hints for this work came from Laboratorio Smaschieramenti, a transfeminist-queer group active in Bologna. After the Grindr datagate scandal, Smaschieramenti organized a series of workshops called frocietariato delle app ${ }^{8}$, 'gay-trans-queer workers of the apps', aimed to open a reflection on the exploitation of sexual and gendered work ${ }^{9}$ done by the users on gay chat and dating apps, and focused on the forms of commodification, frustration and discrimination fostered by this mechanism.

\footnotetext{
${ }^{8}$ The name frocietariato is an ironic reference to Marxist proletariato, 'proletariat' - to highlight the condition of the users as a new digital working class. For further information, Smaschieramenti (2018); Consultoria (2018).

${ }^{9}$ For a specific focus on the wide debate around the reproductive work, in relation to gender a sexuality, CRAAAZi (2018).
} 
One of the main activities organized by frocietariato has been "Share your big data" 10 , a treasure hunt organized in Bologna to redefine the gayqueer map of the city, to subvert the process of privatization and normalization made by these apps, through the use of the apps themselves.

The workshops organized by frocietariato still go on. They provide alternative paths of interpretation and usability, to give more credit and agency to users, along with new practices and discourses to overcome the limits and the control employed by these platforms.

\section{References}

Barthes, Roland. 1972. Mythologies. New York: Hill and Wang.

Barthes, Roland. 1975. The Pleasure of the Text. New York: Farrar, Straus and Giroux.

Baudrillard, Jean. 1981. For a critique of the political economy of the sign. Saint Louis: Telos Press.

Baudrillard, Jean.1994. Simulacres and Simulation. Ann Arbor: University of Michigan Press.

Berardi, Franco. 2002. La Fabbrica dell'Infelicità. New Economy e Movimento del Cognitariato. Roma: DeriveApprodi.

Berardi, Franco. 2011. Time, Acceleration, Violence. e-flux journal. No. 27. September 2011.

CRAAAZì. 2018. Unsafe Words: Per/verso il Valore Queer http://www. craaazi.org/2018/04/29/call/ (last accessed: 14 October 2018).

Consultoria. 2018. Grindr ci Mette a Lavoro: Autoinchiesta sul Frocietariato delle App. https://consultoriaqueerbologna.noblogs.org/ post/2018/04/07/grindr-ci-mette-al-lavoro-autoinchiesta-sul-frocietariato-delle-app/ (last accessed 14 October 2018).

Dusi, Nicola, Marrone, Gianfranco, and Montanari, Federico. 2002. Il Telefonino: Avventure di un Corpo Tecnologico. In Landowski, Eric and Marrone, Gianfranco (eds.). 2002. La Società degli Oggetti. Problemi di Interoggettività. Roma: Meltemi, 166 - 202.

\footnotetext{
${ }^{10}$ The name of the event ironically play both with the scandal of Grindr datagate and with the common practice of sharing hot/sex pictures in the private interaction between users.
} 
Eco, Umberto. 1979a. The Role of the Reader. Bloomington: Indiana University Press.

Eco, Umberto. 1979b. Lector in Fabula. Milano: Bompiani.

Eco, Umberto. 1986. Semiotics and the Philosophy of Language. Bloomington: Indiana University Press.

Ferraro, Guido. 2002. Macchine dell'Immaginario. In Landowski, Eric and Marrone, Gianfranco (eds.). La Società degli Oggetti. Problemi di Interoggettività. Roma: Meltemi, 96 - 115.

Fontanille, Jacques. 2002. La Patina e la Connivenza. In Landowski, Eric and Marrone, Gianfranco (eds.). La Società degli Oggetti. Problemi di Interoggettività. Roma: Meltemi, 71 - 95.

Fumagalli, Andrea. 2015. The Concept of Subsumption of Labour to Capital. Towards the Life Subsumption in Biocognitive Capitalism. In Fisher, Eran \& Fuchs, Christian (eds.). Reconsidering Value and Labour in the Digital Age. London: Palgrave Macmillan.

Greimas, Algirdas. 1983. Structural Semantics: An Attempt at the Method. Lincoln: University of Nebraska Press.

Greimas, Algirdas. 1987. On Meaning. Minnesota: University of Minnesota Press.

Griziotti, Giorgio. 2016. Neurocapitalismo, Mediazioni Tecnologiche e Linee di Fuga. Milano: Mimesis.

Harvey, David. 2012. Rebel Cities: From the Right to the City to the Urban Revolution. London: Verso.

Hjelmslev, Louis. 1985. Nouveaux Essais. Paris: PUF.

Irvine, Judith T. \& Gal, Susan. 2000. Language Ideology and Linguistic differentiation. In Paul V. Kroskrity (ed.). Regimes of Languages: Ideologies, Polities, and Identities. Santa Fe: School of American Research Press, $35-84$.

Landowski, Eric. 2002. Dalla Parte delle Cose. In Landowski, Eric and Marrone, Gianfranco (eds.). La Società degli Oggetti. Problemi di Interoggettività. Roma: Meltemi, 39-46. 
Latour, Bruno. 2002. Una Sociolgia senza Oggetto? Note sull'Interoggettività. In Landowski, Eric and Marrone, Gianfranco (eds.). La Società degli Oggetti. Problemi di Interoggettività. Roma: Meltemi, 203 - 232.

Lazzarato, Maurizio. 2014. Signs and Machine Capitalism and and the Production of Subjectivity. New York: Semiotext(e).

Lotman, Jurij M. 2005. On the Semiosphere. Sign System Studies. No $33,205-229$.

Marrone, Gianfranco. 2002. Dal Design all'Interoggettività: Questioni Introduttive. In Landowski, Eric and Marrone, Gianfranco (eds.). 2002. La Società degli Oggetti. Problemi di Interoggettività. Roma: Meltemi, 9-38.

Negri, Antonio, Vercellone, Carlo. 2007. Il Rapporto Capitale/Lavoro nel Capitalismo Cognitivo. Posse. October 2007, 46 - 56.

Paolucci, Claudio. 2010. Strutturalismo e Interpretazione. Milano: Bompiani.

Pasquinelli, Matteo. 2009. Google's PageRank: A Diagram of Cognitive Capitalism and the Rentier of the Common Intellect. In Becker, Conrad \& Stalder, Felix (eds.). Deep Search: The Politic of Search Beyond Google. 2009. Innsbruck: StudienVerlag, $32-48$.

Pasquinelli, Matteo 2009b. Oltre le Rovine della Città Creativa: La Fabbrica della Cultura e il Sabotaggio della Rendita. In Marco Baravalle (ed.). 2009. L'Arte della Sovversione. Roma: Meltemi. 47 - 63.

Raunig, Gerard. 2010. A Thousand Machines: A Concise Philososphy of the Machine as a Social Movement. New York: Semiotext(e).

Semi, Giovanni. 2015. Gentrification: Tutte le Città come Disneyland? Bologna: Il Mulino.

Semprini Andrea. 2002. Oggetti senza Frontiere. In Landowski, Eric and Marrone, Gianfranco (eds.). La Società degli Oggetti. Problemi di Interoggettività. Roma: Meltemi, 47 - 61.

Smaschieramenti. 2018. Frocietariato delle App di Grindr e salute. https://smaschieramenti.noblogs.org/post/2018/04/07/frocietariato-delle-app-di-grindr-e-salute/ (last accessed 14 October 2018). 
Vercellone, Carlo. Il Ritorno del Rentier: Salario, Rendita e Profitto nel Capitalismo Cognitivo. Posse. 97 - 111.

Vercellone, Carlo. 2007. From Formal Subsumption to General Intellect: Elements for a Marxist Reading of the Thesis of Cognitive Capitalism. 2007. Historical Materialism. No. 15, 3-36.

Violi, Patrizia. 2014. Paesaggi della Memoria. Milano: Bompiani.

Zukin, Sharon. 1987. Gentrification: Culture and Capital in the Urban Core. Annual Review of Sociology. No. 13, 129 - 147. 